\title{
Understanding basics of Six Sigma
}

\author{
Arunesh Patel \\ Mechanical Engineering Dept. \\ ITM Universe, Vadodara \\ Vadodara, India
}

\author{
Chintan Chudgar \\ Mechanical Engineering Dept. \\ ITM Universe, Vadodara \\ Vadodara, India
}

\begin{abstract}
Six sigma is the control methodology used to avoid variations or correction in the project. Six sigma is applied before implementation of the new project to study and analyze the certainty of risk. Six sigma team is the group of team is the group of six sigma scholars employed by the organization to work on the error faced by the institute by reducing the loss and increasing the profit. Six sigma team consist of member who achieved training in six sigma and equipped with six sigma belts such as White belt, Green belt, Black belt and Master black belt. Six sigma process consists of five stages demoted as DMAIC, namely, Define, Measure, Analyze, Improve, Control. Each stage uses tools and techniques such as software like Minitab which are used to test normality of the data. Preferred Six sigma level for the organization is selected by comparing its defects per million opportunity (DPMO) with that of six sigma levels. By applying all the tools and techniques, desired output is achieved.
\end{abstract}

Keywords - Six sigma, Risk analysis, Six sigma belts, DMAIC, minitabs, Six sigma level, DPMO, DMADV, MSA, SMART, SIPOC

\section{INTRODUCTION}

We all get stuck. We attempt to make improvements to our products, our processes, our services, but we fail because we are clueless about the key factors that drive performance. So, how do we get unstuck? What tools and techniques can we use to improve our performance? The answer is Six Sigma $(6 \sigma)$. So, what is six sigma? Six sigma is defined as a projectbased approach for improving effectiveness and efficiency. It is a disciplined, customer-focused, data-driven approach for improving the performance of processes, products, or services. Six sigma is a proactive and prevention-based method instead of reactive and detection based. Six sigma refers to a level is quality that is near perfection and there are no more than 3.4 defect parts per million. Sigma $(\sigma)$ is a letter in the Greek alphabet used to represent standard deviation which is a measure of variation. There are two types of problem-solving methodology in six sigma one is DMAIC and another is DMADV. DMAIC stands for Define, Measure, Analyse, Improve, and Control whereas DMADV stands for Define, Measure, Analyse, Design and Verify. For ease of understanding, let's take a day to day life example. Take the standard experience of calling a cable company for installation or repair. You call them, and they say, the earliest we can get a technician out to your house is 10 working days from today. And, the technician will be there sometime between 8:00 a.m. 5:00 p.m. Fast forward 10 days. You have taken a day off work to stay home and wait for the technician. And you wait, and you wait. Then the technician either doesn't show or shows up late, past 5:00 p.m. Wouldn't it be nice if instead they said, we can get the technician out to your house tomorrow, between 8:00 and 8:30 a.m. And the next day, the technician shows up at 8:00 a.m. That during a nutshell is what Six Sigma can do.

\section{EXECUTIVES AND CHAMPION}

In six sigma there are terms like six sigma executives and project champion.

Executives are CEO and his or her direct report like COO, $\mathrm{CFO}, \mathrm{CIO}$, etc. and senior management like vice presidents or directors. Once the decision has been made to implement the six sigma project, the role of executives and senior management is to deploy six sigma projects to meet the company's strategic and annual goals. They also establish project selection criteria, review, and select a project. They assign project champion to project and review updates from champions. They also provide resources when needed.

The champion, also known as Project Champion, is an executive's point person whose role is to ensure the success of the project. Normally, the champion is an executive or senior manager who has clout and respect to ensure that the project has the correct resources, time, and priority that it needs. The project champion selects the project leader. The role of the project leader is to plan, lead, and execute the project with the designated project team. The project champion also approves the project charter. The project charter is a document that defines the project including the objectives, timeline, and scope. Champion also select the project team and launch the project. They also provide time and resources for the project team to work on the project. The champion closely monitors the progress of the project by receiving updates from the project leader every week and removes obstacles if any.

Correctly understanding the roles of the executives and the project champion is pivotal as your organization implements Six Sigma.

\section{LEVELS OF EXPERTISE IN SIX SIGMA}

The belts in martial arts were adapted to recognize the different levels of expertise in six sigma. So, let's look into the different types of belts, types of training received by each belt, and their contribution to the implementation of six sigma. The belts in order of expertise are:

1. White belt

2. Yellow belt

3. Green belt

4. Black belt

5. Master black belt

Now, let's study each belt in detail.

1. White belt

- White belt training introduces to the basic six sigma concepts including quality and process thinking.

- White belt training is knowledge-based training. 
- An introductory overview of six sigma is given in white belt training.

- White belt training motivates interest and understanding in six sigma.

2. Yellow belt

- In yellow belt training, DMAIC methodology is introduced.

- The simple process and quality tools used are taught. For example, the concept of variation, voice-of-customer analysis, process mapping, and brainstorming for root cause analysis.

- Yellow belts are trained to lead and facilitate improvement sessions using these tools.

- They also serve as team members on a green belt DMAIC project.

3. Green belt

- Green belt training takes participants through each phase of DMAIC.

- In addition to process and quality tools, data analysis through statistics is taught.

- Green belt participants come into training with the DMAIC project already assigned to them. They will apply what they learn to their projects in training sessions.

- Green belt participants are trained to lead and carry out DMAIC projects on a parttime basis.

4. Black belt

- Black belts are full time six sigma specialists.

- $\quad$ They lead and carry out complex projects assigned to them by senior management.

- They are given training in advanced quality and statistical tools which are used in six sigma. For example, process capability, inferential statistics, and design of experiment(DOE).

\section{Master black belt.}

- Master black belt receives additional training like advanced statistical analysis, process simulation, project management, and change management.

- They serve as six sigma trainers and coaches to the rest of the organization.

\section{SIGMA LEVELS}

In this topic, let's discuss the sigma level, how sigma level is used, and what does it mean to be at two sigma, three sigma or six sigma. Sigma level is a performance metric used to indicate the quality level of product, process, or services. Always remember one rule, higher the sigma level, better the performance. Six sigma level performance means that there are no more than 3.4 DPMO (Defects Per Million Opportunities), which us equivalent to $99.99966 \%$ good.
Refer the following table for more details:

\begin{tabular}{|c|c|c|}
\hline & SIG & \\
\hline SIGMA LEVEL & DPMO & \% GOOD \\
\hline 1 & 690,000 & $31.000 \%$ \\
\hline 2 & 308,537 & $69.1463 \%$ \\
\hline 3 & 66,807 & $93.31933 \%$ \\
\hline 4 & 6.210 & $99.379 \%$ \\
\hline 5 & 233 & $99.9767 \%$ \\
\hline 6 & 3.4 & $99.99966 \%$ \\
\hline
\end{tabular}

Sigma level scale is not linear. Improving from two sigma to three sigma is a 5 times order of magnitude in a reduction of a defect. But, improving from three sigma to four sigma is a 10 times order of magnitude in the reduction of defects. Sigma level provides a common yardstick to compare the performance of different products, processes, and services.

\section{$\mathrm{V}$ SELECTION OF SIX SIGMA PROJECT}

The selection of six sigma project consists of two parts, one is identifying potential project and the second selection of six sigma team. Let us study both of them in detail.

\section{A. Identify potential project}

We always have a question that we ask our self, "how do we identify six sigma project? what should be screening criteria? and, how do I prioritize the project?". Here we will discuss how to identify the project for six sigma and then we will discuss how to screen them and prioritize them for launch.

Start with the company's or department's annual goal

$\checkmark$ What improvements are needed?

$\checkmark$ How do you plan to achieve those improvements?

$\checkmark$ What six sigma project will help you to achieve those goals?

- Identify performance gaps in key metrics, key performance indicators, KPIs

$\checkmark \quad$ Do these gaps have to be closed?

\# Review performance reports on products, services, and processes. Identify areas with performance shortfalls.

* Review data on customer complaints, returns, warranties, claims, and credits. Areas with a high number of complaints, returns or credits indicate deficiencies. These deficiencies are potential targets for six sigma projects.

* Audits provide a good source for potential projects. Any recurring findings or chronically poor performance are potential targets.

* Employee suggestions are another source for identifying projects.

* Once the potential projects are identified, you have to screen them to see if six sigma is appropriate. Following screening criteria should we use:

$\checkmark \quad$ The performance deficiency should be a recurring or chronic issue, meaning it should not be a one-off or one-time occurrence. 
$\checkmark \quad$ An opportunity should be specific, specific to a particular product, process, or service.

$\checkmark \quad$ It should be measurable. Remember you cannot improve what you cannot measure.

$\checkmark$ Improvement opportunities should have a significant operational and financial impact.

$\checkmark$ There must be alignment. The project should help in achieving and goals and targets which are set by senior management.

$\checkmark \quad$ The potential project must pass every one of these screening criteria.

Senior management prioritizes and selects the project to launch.

* Following factors should be considered while prioritizing the project:
$\checkmark$ Financial impact
$\checkmark \quad$ Degree of urgency
$\checkmark$ Impact on customers
$\checkmark$ Difficulty in execution
$\checkmark \quad$ Level of changes

\section{B. Select the six sigma team}

* Champion: Team owner

$\checkmark$ Organizes and supports the project

Typically, a senior manager

Project leader: Team captain

$\checkmark \quad$ Leads the team

$\checkmark \quad$ Executes the project

\section{Team members}

$\checkmark \quad$ Selected by champion and leader

$\checkmark$ Should select the individuals with experience and expertise.

VI DMAIC: PROBLEM SOLVING METHODOLOGY DMAIC, Define, Measure, Analyse, Improve, and Control. The first three steps, define, measure, and analyze, are called process characterization. The last two steps, improve and control, are called optimization.

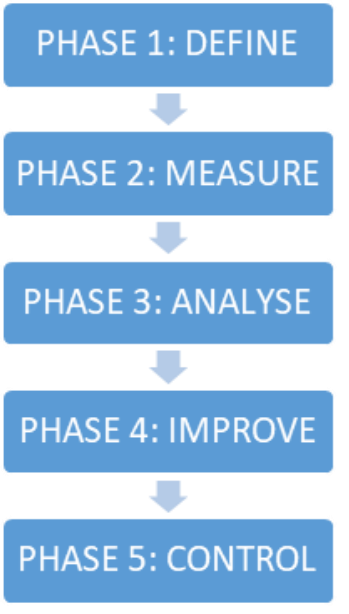

Fig. 1. Phases of DMAIC

\section{TABLE II. DMAIC METHODOLOGY}

\begin{tabular}{|c|c|}
\hline 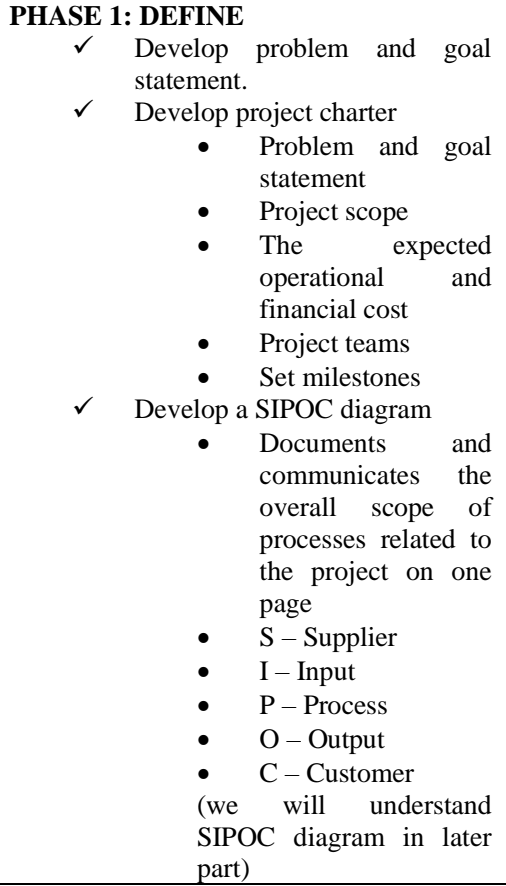 & $\begin{array}{cl}\text { PHASE 2: } & \text { MEASURE } \\
\checkmark & \text { Develop a data } \\
& \text { collection plan } \\
\checkmark & \text { Define CTQs } \\
\checkmark & \text { Map relevant } \\
& \text { processes } \\
\checkmark & \text { Identify inputs and } \\
\checkmark & \text { output } \\
& \begin{array}{l}\text { Develop a } \\
\text { measurement plan } \\
\text { and validate it. }\end{array}\end{array}$ \\
\hline $\begin{array}{cl}\text { PHASE 3: } & \text { ANALYSE } \\
\checkmark & \text { List potential inputs that can } \\
& \text { impact overall output. } \\
\checkmark & \text { Organize potential inputs. } \\
\checkmark & \text { Shortlist and select key inputs. } \\
\checkmark & \text { Develop a data collection plan } \\
& \text { for analysis. } \\
\checkmark & \text { Develop an input-output } \\
& \text { relationship. } \\
\checkmark & \text { Identify critical paths. } \\
\checkmark & \text { Develop FEMA ( Failure Mode } \\
& \text { and Effect Analysis) } \\
\end{array}$ & $\begin{array}{cl}\text { PHASE 4: IMPROVE } \\
\checkmark \quad \text { Generate potential } \\
& \text { solutions for } \\
& \text { proven key inputs. } \\
\checkmark & \text { Find solution } \\
\checkmark & \text { alternatives. } \\
& \text { The select right set } \\
& \text { of solutions to } \\
& \text { implement. } \\
& \text { Reduce variability } \\
\text { and compute } & \text { sigma. }\end{array}$ \\
\hline $\begin{array}{l}\text { Develop a control plan. } \\
\qquad \quad \text { Monitor, control, and } \\
\text { Control of key inputs to ensure in } \\
\text { Work with process owners to upd } \\
\text { Implement and monitor performa } \\
\text { Validate financial impact. } \\
\text { Secure project completion sign-o }\end{array}$ & $\begin{array}{l}\text { egulate performance. } \\
\text { oroved output is sustainable. } \\
\text { te procedures. } \\
\text { ce. }\end{array}$ \\
\hline
\end{tabular}

\begin{tabular}{|l|l|}
\hline & PABLE III. PROCESS MAP SYMBOLS \\
\hline & Activities \\
\hline & Decision \\
\hline & Sequence of flow \\
\hline
\end{tabular}

Points to remember: -

1) The goal statement should be SMART

- S - Specific, the goal statement must be specific about its objectives in each area of the project and can clearly state its purpose of the initiation.

- $\quad \mathbf{M}$ - Measurable, the goal statement must be measurable about what, when, and why after you reach the goal. Measurable means 
categorizing down your process into measurable elements.

- A - Attainable, the goal statement must be Achievable to complete a project. Every step, process, or operation must be within its limit where it is possible to achieve.

- $\mathbf{R}$ - Relevant, the goal statement must relevant about the timing, training, and importance before taking it into account or action. The project champion must understand the perfect timing and environment before the execution of the project idea.

- $\mathbf{T}$ - Time-bound, the goal statement must be time-bound to complete or start the project in time. The project must be completed the preferred time frame discussed by the stakeholders and managers to be consistent with other projects.

2) While mapping current processes,

- Involve people who know the process

- Use logical orientation

\section{A. How to ANALYZE Process Charts}

Following steps are to be followed to analyze process maps: -

1) Identify any bottlenecks

$\checkmark$ Where is the delay?

$\checkmark$ Where are holdups?

$\checkmark \quad$ Why bottlenecks are present?

2) Identify any workarounds

3) Focus on decision diamonds

$\checkmark$ Inspections

$\checkmark$ Checks

$\checkmark$ Evaluation decision

4) Look at rework loops

$\checkmark$ How long are they?

5) Shorten the rework loop

\section{B. CRITICAL-TO-QUality (CTQ) AND Voice OF CUSTOMER (VOC)}

At the beginning of the defined phase, Voice of Customer(VOC) is collected to define requirements, expectations, comments, preferences of the customer for the product or service before actually starting of Implementing the idea. Different methods are used to collect VOCs. Special teams like marketing, IT, etc. are used to collect and file VOCs.

CTQ's are known as critical-to-quality which shows the need of the customer regarding different measurements. CTQ's are the part of VOC where a chart is made regarding different needs of the customer and what are the required inputs to be given to get desired outputs. Let us understand CTQ and VOC with an easy example.

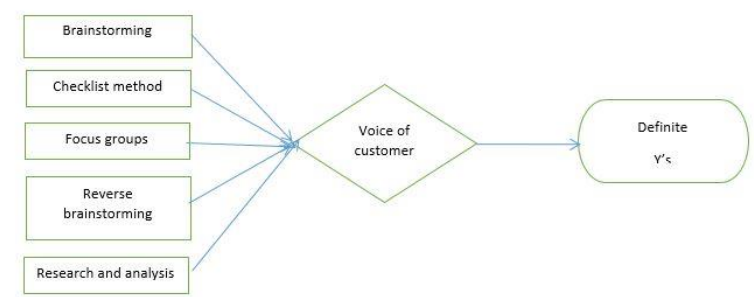

\section{CTQ Tree}

Fig. 2. Voice Of Customer

- VOC:" I have to wait for 1.5 hrs. for my pizza to arrive"

- CTQ name: - Delivery time

- CTQ measure: - Hours and Minutes (HH: MM)

- CTQ requirements: - less than 45 minutes to deliver pizza

- Defect: - 5 pizza delivery per hour

- Unit: -pizza

- Opportunity: - decrease preparation time, increase oven temperature, take a shorter route, decrease baking time

\section{SIPOC DIAGRAM}

SIPOC is not just an arrangement of letters but it is the process that is done initially to give formal and legal information to the person unfamiliar with the process. SIPOC diagram is an overview of the whole system from the supplier to the consumer, this helps in getting the idea of the company's interaction outside the premises. This is the eagle's eye view of the company's interaction and relation with suppliers and consumers.

SIPOC diagram consists of 5 elements as the name suggests that is Supplier, Input, Process, Output, Consumer.

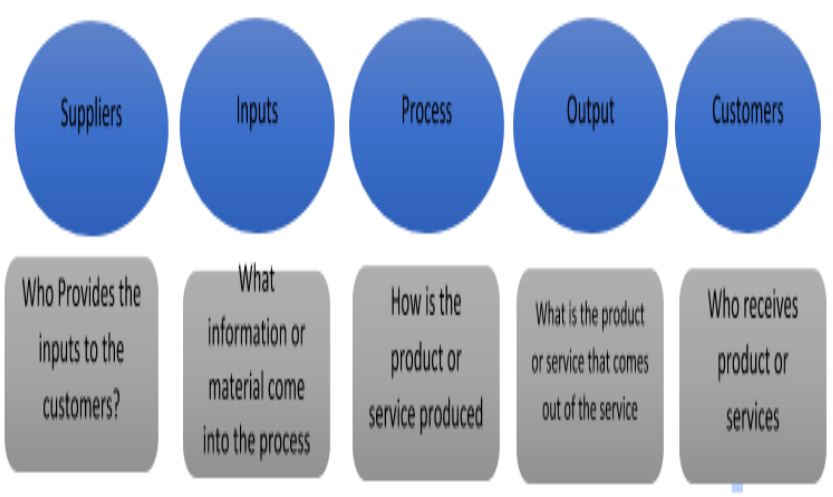

Fig. 3. SIPOC DIAGRAM 


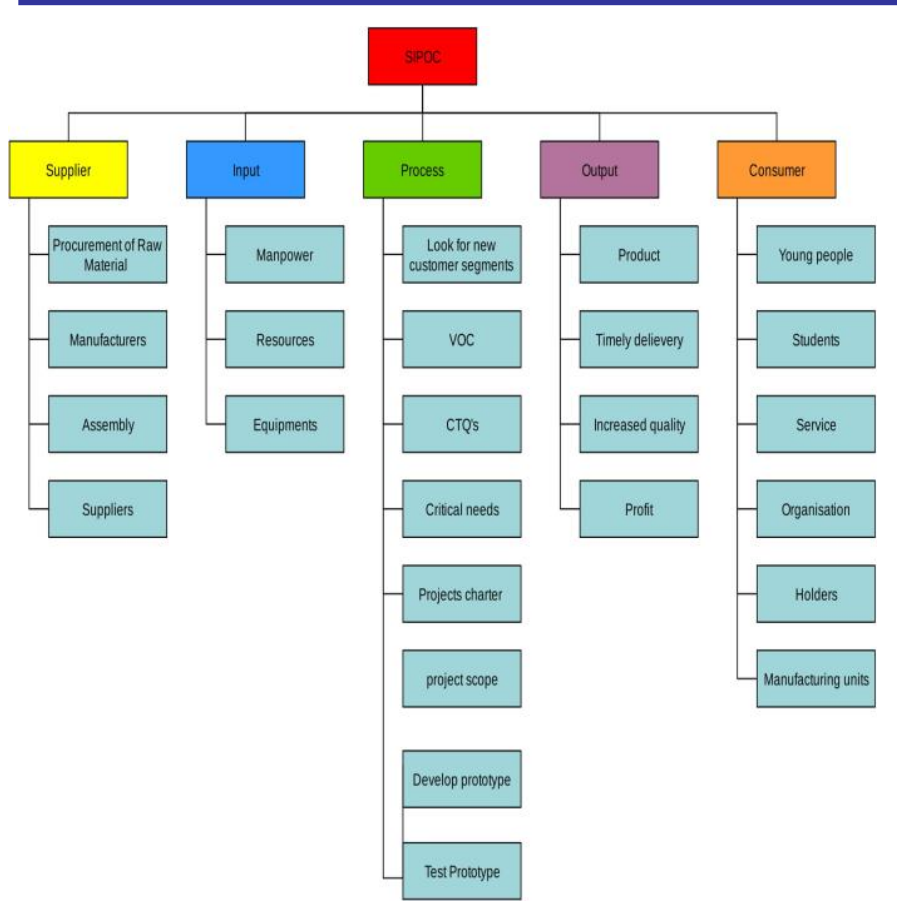

Fig. 4. SIPOC DIAGRAM COMPONENTS

\section{MEASURENT SYSTEM ANALYSIS (MSA)}

During the measure phase, not only taking the measurements are important but it is mandatory for the system to be accurate throughout the process. This accurate reading will directly affect the Improve and Control phase. To ensure the consistency and accuracy of data, different charts are used by inserting and running different data using software like Minitab.

Different terminologies used in MSA are:

i. Discrimination- Minimum incremental difference between two measured values.

ii. Accuracy-Difference between baseline value and observed value.

iii. Stability- The observed value of at least 2 measurements by two operators should be the same.

MSA plays a very important role in six sigma. It helps in determining the variance by using the mathematical and theoretical analysis by software to determine the amount of error in comparison to baseline.

\section{There are 5 types of Parameters to observe: -}

1. Reproducibility

2. Stability

3. Linearity

4. Repeatability

5. Bias

The error to be detected depends on two things.

1) The instrument used for measurement. (repeatability)

2) The person operating the instrument. (Reproducibility)

\section{How much error is acceptable in MSA?}

- Less than $10 \%$ is considered as accurate

- $10 \%$ to $30 \%$ is considered acceptable after studying the importance of the project, cost, use, etc.

- More than $30 \%$ is rejected and the error must be corrected before applying.
The only purpose to use MSA in six sigma is to get Accuracy, precision, and stability in the process to match the sigma level DPMO.

\section{E. DESIGN OF EXPERIMENTS (DOE)}

Design of experiments (DOE) is the six sigma tool used in analyze phase. The main objective of DOE is to observe and modify the input variable by monitoring the change in output. DOE give the exact change in the final product by changing the input.

The process of DOE is simple and visual hence it is easy to decode. The process consists of 3 major steps such as

- Factors-Factors are the change in input which is decided by project team during the brainstorming session.

- Levels-Levels are just the number of factors that can affect the process success. They are the settings at which the experiments are to be carried out.

- Response-The final step is to evaluate the output of DOE and discussion with the respective department regarding improvements of the process and choosing the best response to eliminate the error.

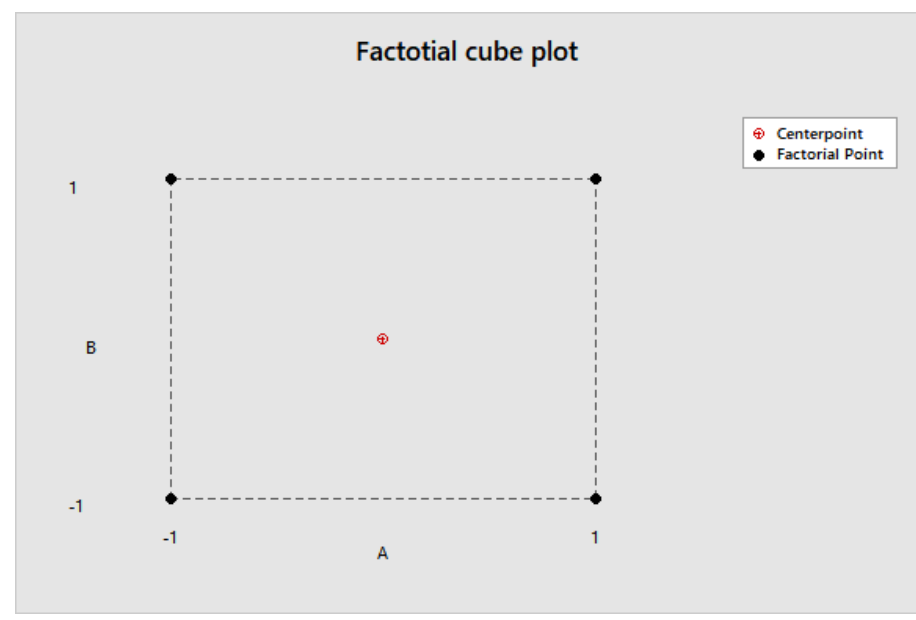

Fig. 5. Factorial Cube plot

\section{F. STATISTICAL PROCESS CHART (SPC)}

After completion of all the phase in DMAIC the final process and continuous process will be construction and monitoring of statistical process control charts (SPC charts). Control phase according to theory is the easiest phase, while it is most difficult phase in six sigma methodology. Constant monitoring and data is done using the time frame. Each constraint is measure with respect to time. After collection of data there are numerous control charts to select and use.

Construction of control charts include one mid line, one bottom line and one top line. The top line is called upper control limit (UCL) and the bottom line is known is lower control line (LCL). Both the UCL and LCL can be derived from the previous data.

Plotting of data in control charts are simple

- Open software for producing control charts

- Input UCL and LCL for the chart

- Input data recorded

- Select okay and plot the chart. 
There are certain conditions that can be observed in the charts which will prove the uncertainty of the process.

- 9 points in a row on the same side.

- 6 points in a row all increasing or decreasing.

- 14 points in a row fluctuating up and down on the same side.

- 2 out of 3 points having more than 2 standard deviations from center.

- 4 out of 5 points more than 1 standard deviation from center.
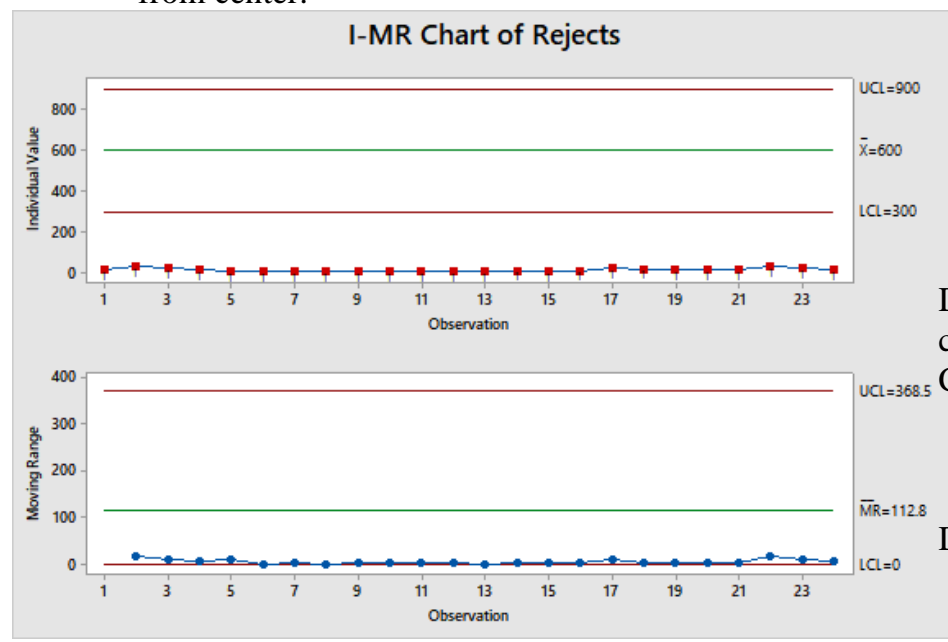

Fig. 6. IiMR Chart of rejcts

\section{G. DMAIC VS DMADV}

\begin{tabular}{|c|c|}
\hline DMAIC & DMADV \\
\hline DEFINE & DEFINE \\
\hline $\begin{array}{l}\text { Define the project goals and } \\
\text { customer deliverables. }\end{array}$ & $\begin{array}{l}\text { Define the project goals and } \\
\text { customer deliverables. }\end{array}$ \\
\hline MEASURE & MEASURE \\
\hline $\begin{array}{l}\text { Measure the process to } \\
\text { determine the current } \\
\text { performance. }\end{array}$ & $\begin{array}{l}\text { Measure and determine } \\
\text { customer needs and } \\
\text { specifications. }\end{array}$ \\
\hline ANALYZE & ANALYZE \\
\hline $\begin{array}{l}\text { Analyze and determine the } \\
\text { root cause of a defect. }\end{array}$ & $\begin{array}{l}\text { Analyze the product or } \\
\text { process options to meet } \\
\text { customer needs. }\end{array}$ \\
\hline IMPROVE & DESIGN \\
\hline $\begin{array}{l}\text { Improve the process by } \\
\text { eliminating defects. }\end{array}$ & $\begin{array}{l}\text { Design (detailed) the product } \\
\text { or process to meet customer } \\
\text { needs. }\end{array}$ \\
\hline CONTROL & VERIFY \\
\hline $\begin{array}{l}\text { Control future } \\
\text { performance. }\end{array}$ & $\begin{array}{l}\text { Verify the design } \\
\text { performance and ability to } \\
\text { meet customer needs. }\end{array}$ \\
\hline
\end{tabular}

\section{When to use DMAIC?}

DMAIC methodology should be used when a product or process is in existence at your company but it is not meeting customer specifications or is not performing adequately.

When to use DMADV?

DMADV methodology should be used when:

* A product or process is not in existence at your company and one needs to be developed.
* The product or process exists and has been optimized (using either DMAIC or not) and still does not meet the level of customer specification or six sigma level.

\section{TYPES OF DATA AND GRAPHS USED IN SIX SIGMA}

Six sigma uses different types of data and graphs. Let us discuss about this in detail in this section.

Mainly, data are of two types:

1. Continuous data: Continuous data is a type of data which can be measured. It is value on a continuum. For example, inches, centimetres, pounds, kilogram, etc. Value can be in decimal or fraction form also.

2. Discrete data: Discrete data is a type of data which can be counted. Values like integers, whole number. They are also called categorical data.

Data types impact the type of graph that can be used. For continuous data graphs can be used to variations.

Continuous data and graphs and charts include:
$\checkmark$ Histograms
$\checkmark$ Dot plots
$\checkmark$ Box plots

Discrete or categorical data graphs and chart include:
$\checkmark$ Bar charts
$\checkmark$ Pareto charts

Graphs showing trends over time are:
$\checkmark \quad$ Line graph
$\checkmark \quad$ Time series charts
$\checkmark$ Control charts

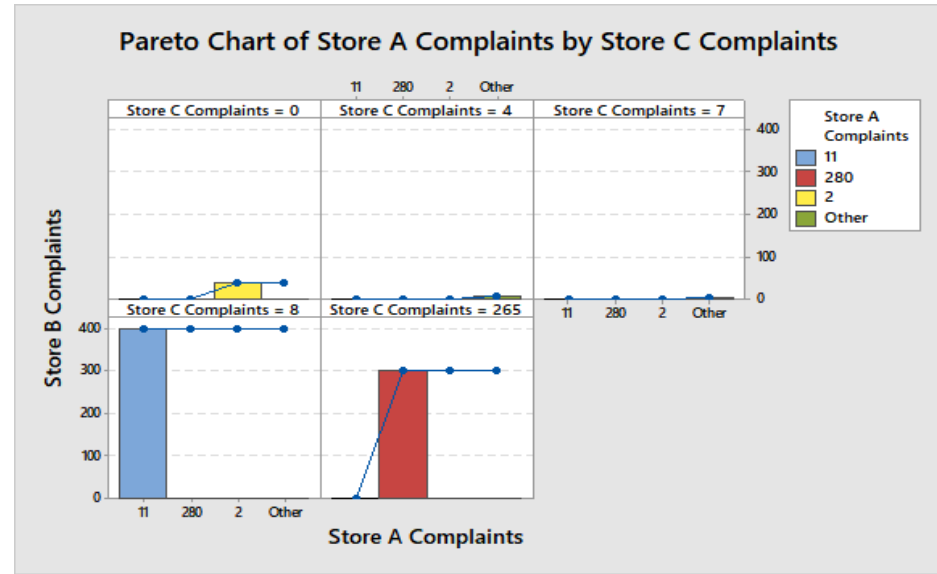

Fig. 7. EXAMPLE OF PARETO CHART

Dotplot of Store A Comp, Store B Comp, Store C Comp, Store D Comp,

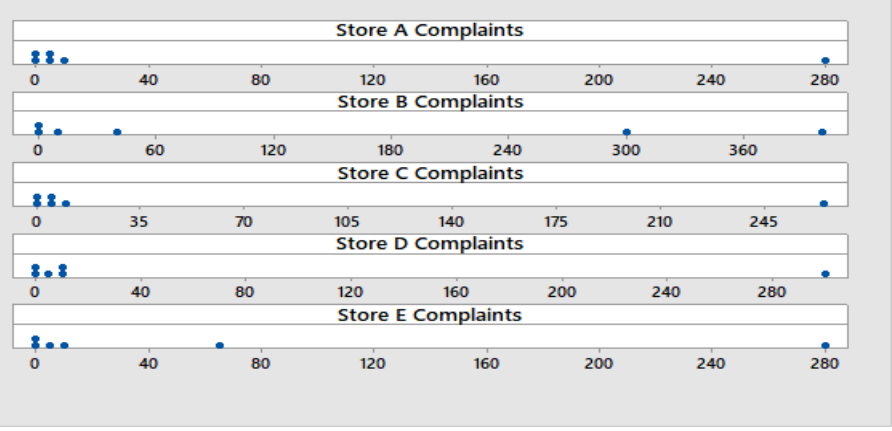

Fig. 8. EXAMPLE OF DOTPLOT CHART 
Boxplot of Store A Comp, Store B Comp, Store C Comp, Store D Comp, ..

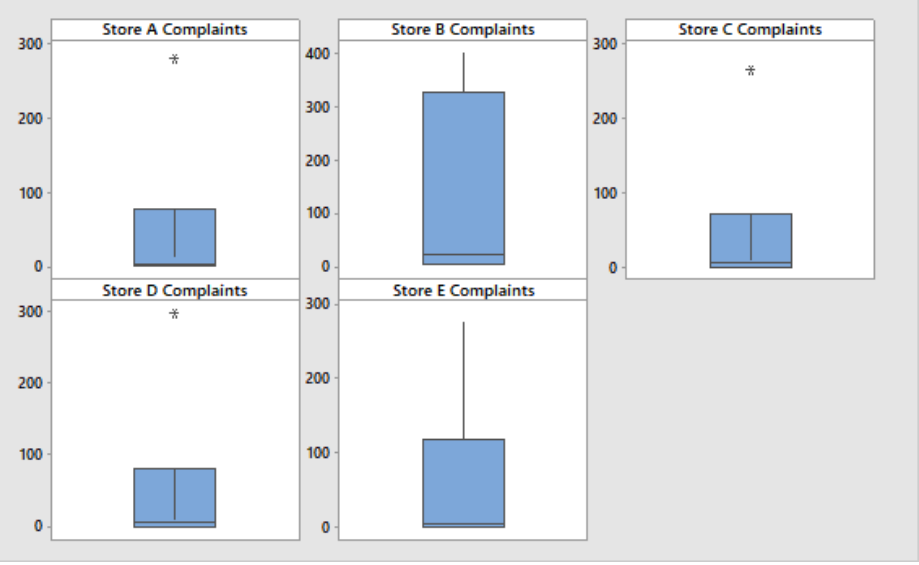

Fig. 9. EXAMPLE OF BOXPLOT CHART

\section{REFERENCES}

[1] The American Society for Quality, Inc. (ASQ)

[2] Villanova University.com

[3] B Tjahjono*, P Ball, V I Vitanov, C Scorzafave, J Nogueira, J Calleja, M Minguet, L Narasimha, A Rivas, A Srivastava, S Srivastava and A Yadav Manufacturing Department, School of Applied Sciences, Cranfield University, Cranfield, Bedford MK43 0AL, UK (2010) doi:DOI: 10.1108/20401461011075017 "Six sigma: a literature review"

[4] Aghili, S. (2009), "A Six Sigma Approach to Internal Audits", Strategic Finance, vol. 90, no. 8, pp. 38-43

[5] Al-Mishari, S.T. and Suliman, S. (2008), "Integrating Six-Sigma with other reliability improvement methods in equipment reliability and maintenance applications", Journal of Quality in Maintenance Engineering, vol. 14, no. 1, pp. 59-70

[6] Antony, J. (2007), "Is six sigma a management fad or fact?", Assembly Automation, vol. 27, no. 1, pp. 17-19

[7] Hagemeyer, C., Gershenson, J. K. and Johnson, D. M. (2006), "Classification and application of problem solving quality tools", TQM Magazine, vol. 18 , no. 5, pp. 455-483

[8] Haikonen, A., Savolainen, T. and Järvinen, P. (2004), "Exploring Six Sigma and CI capability development: Preliminary case study findings on management role", Journal of Manufacturing Technology Management, vol. 15, no. 4, pp. 369-378

[9] Halliday, S. (2005), "Application of Tools in Six Sigma", http://www.wdpc.co.uk/articles/tools6sig.pdf, last accessed 25 November 2009

[10] Kwak, Y.H. and Anbari, F.T. (2006), "Benefits, Obstacles and future of Six Sigma approach", Technovation, vol. 26, no. 5-6, pp. 708-715

[11] Kumar, S., Jensen, H. and Menge, H. (2008), "Analyzing Mitigation of Container Security Risk Using Six Sigma DMAIC Approach in Supply Chain Design", Transportation Journal, vol. 47, no. 2, pp. 54-67

[12] Lee-Mortimer, A. (2006), "Six Sigma: a vita improvement approach when applied to the right problems, in the right environment", Assembly Automation, vol. 26, no. 1, pp. 10-17

[13] Montes, F.J.L. and Molina, L.M. (2006), "Six Sigma and Management Theory: Processes, Content and Effectiveness", Total Quality Management, vol. 17, no. 4, pp. 485-506

[14] Ward, S.W, Poling, S.R. and Clipp, P. (2008), "Selecting Successful Six Sigma Projects", Quality, vol. 47, no. 10, pp. 5051

[15] Six Sigma - A New Direction to Quality and Productivity Management, Tushar N. Desai and Dr. R. L. Shrivastav, WCECS 2008, ISBN: 978-988-98671-0-2 